Pediat. Res. 4: 280-285 (1970)

Anemia erythroblastosis

hypoglycemia insulin

kidney

newborns

urine

\title{
Hypoglycemia and Excretion of Insulin in Urine in Hemolytic Disease of the Newborn
}

\author{
D. SchIFF ${ }^{[19]}$ and C. LowY \\ Neonatal Research Institute, Institute of Child Health, and the Department of Medicine, \\ the Royal Postgraduate Medical School, Hammersmith Hospital, London, England
}

\begin{abstract}
Extract
Blood glucose levels and rates of excretion of insulin in urine were measured in 31 infants with erythroblastosis. Twenty-two of these infants had determinations of insulin excretion in urine performed during the first $24 \mathrm{~h}$ of life. These infants can be divided into two groups. Group I were infants of greater than 36 weeks gestation. When using hemoglobin as the index of severity of the disease, they can be subdivided into two groups. Group $1 \mathrm{~A}$ (six infants with a cord hemoglobin value of greater than $13 \mathrm{~g} / 100 \mathrm{ml}$ ) had a mean excretion ratio of insulin/creatinine in urine of $6.9 \mu \mathrm{U} / \mathrm{mg}$ compared with a mean of $5.4 \mu \mathrm{U} / \mathrm{mg}$ for the control group $(P=0.5)$. Group $1 \mathrm{~B}$ (six infants with a cord hemoglobin value of less than $13 \mathrm{~g} / 100 \mathrm{ml}$ ) had a mean value for insulin in the urine of $47.0 \mu \mathrm{U} / \mathrm{mg}$, compared with a mean value of $5.4 \mu \mathrm{U} / \mathrm{mg}$ for the control group. Group 2, composed of 10 infants of less than 36 weeks gestation, had a mean value for insulin in urine of $129.7 \mu \mathrm{U} / \mathrm{mg}$, compared with a mean of $21.9 \mu \mathrm{U} / \mathrm{mg}$ for the control group $(P<0.01)$. Excretion of insulin was inversely related to blood glucose. Seven infants were hypoglycemic (blood glucose levels of less than $20 \mathrm{mg} / 100 \mathrm{ml}$ ) and all had elevated insulin levels in urine.
\end{abstract}

\section{Speculation}

In erythroblastotic infants, simultaneous occurrence of islet cell hyperplasia, hypoglycemia, and hyperinsulinuria is indicative of increased insulin production. The cause of the islet cell hyperplasia is not apparent. The placenta is commonly hyperplastic, and hence, its ability to destroy insulin may be enhanced, thus causing islet cell hyperplasia. At birth, separation of the infant from the placenta leads to an abrupt decrease in the infant's rate of insulin destruction, and thus, to temporary overproduction of insulin. This hypothesis is in keeping with the observed early hypoglycemia and the normal birth weight for gestational age.

\section{Introduction}

In infants with hemolytic disease due to $\mathrm{Rh}$ incompatibility, islet cell hyperplasia was recognized over 30 years ago $[5,8]$. More recently, insulin content of the pancreas under these conditions has been found to be increased [3]. Although Miller et al. [7] dem- onstrated several similarities at autopsy between infants of diabetic mothers and erythroblastotic infants, hypoglycemia in the latter group has only recently been recognized $[1,4]$. This study reports on the relation between hypoglycemia and hyperinsulinism in such infants using excretion of insulin in the urine as an index of insulin secretion. 


\section{Methods and Patients}

Insulin was measured by a double antibody radioimmunoassay [10], using human insulin as the standard [17]. Wherever possible, samples were estimated at three dilutions $(0.1,0.5$ and $1 \mathrm{ml})$. Values were expressed as microunits of insulin per milligram of creatinine. Since insulin excretion is log normally distributed [6], the mean and SEM were calculated from the logarithmic values and the scale used in the diagrams is a logarithmic one. Glucose was determined on whole blood using a glucose oxidase micromethod [14].

Infants

Thirty-one Goombs-positive erythroblastotic infants were studied. Their gestational ages ranged from 27 to 39 weeks, and their birth weights from 0.93 to $3.7 \mathrm{~kg}$. The weight of one infant was above the 90 th percentile and the weight of one was below the 10th percentile for the stated gestational age. Measurements of insulin in urine were determined in 22 of 31 infants during the first $24 \mathrm{~h}$ of life; clinical details are shown in table I.

Forty-five normal term infants studied concurrently served as one control group [6]; thirteen normal premature infants served as controls for the premature erythroblastotic infants. The premature infants received pooled breast milk on an hourly schedule in volumes of $60 \mathrm{ml} / \mathrm{kg} / 24 \mathrm{~h}$ [12].

\section{Blood Glucose Estimations}

At birth, cord blood was analyzed for hemoglobin, bilirubin, and glucose. Catheters were inserted into the umbilical vein in 17 infants requiring immediate exchange transfusions. In such cases, blood for serial glucose estimations was obtained from the catheter site prior to and after the exchange transfusion. In the remaining instances, capillary blood was used to measure serial glucose levels [18]. Owing to the considerable variation in clinical status of the infants not all variables were studied in each case. Concentrations of glucose in blood were measured in 30 infants during the first $24 \mathrm{~h}$ of life. Serial estimations were made in all infants except four who were only mildly affected. Blood glucose was monitored in 11 of the 13 healthy premature infants studied. No blood glucose measurements were made in the healthy mature infants. Hypoglycemia was defined as a true glucose of less than 20 $\mathrm{mg} / 100 \mathrm{ml}$ occurring twice within a $24-\mathrm{h}$ period.

\section{Insulin in Urine}

Urine was collected from 22 erythroblastotic infants, 13 uncomplicated premature infants, and 45 normal mature infants, from the first voiding after birth for periods ranging from 12 to $24 \mathrm{~h}$. Urine collections were continued during exchange transfusions in 14 erythroblastotic infants (table I).

\section{Blood Glucose}

Results

Blood glucose values in the erythroblastotic infants are illustrated in figure 1. Six premature erythroblastotic infants and one term erythroblastotic infant were hypoglycemic within the first $6 \mathrm{~h}$ of life. Also, one term and one premature erythroblastotic infant had a single glucose reading below $20 \mathrm{mg} / 100 \mathrm{ml}$. Hypoglycemia was not found in any of the normal premature infants studied.

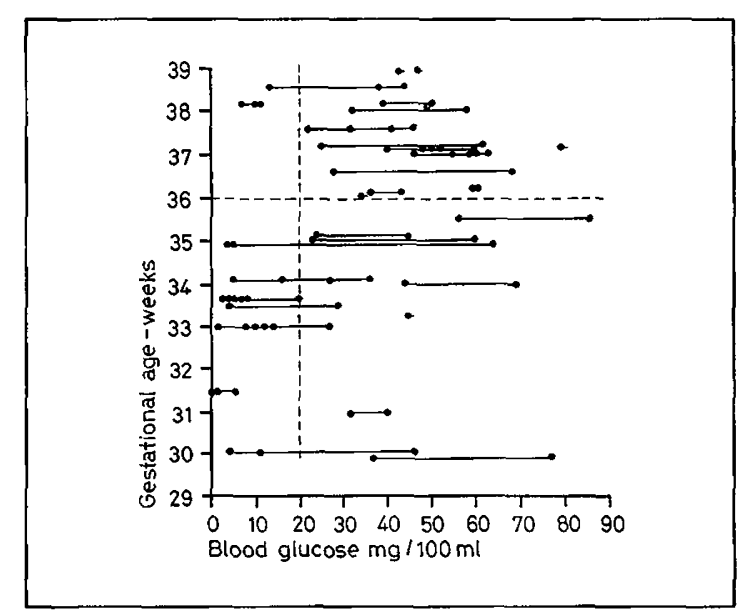

Fig. 1. Estimations of glucose in blood in 30 erythroblastotic infants within the first $24 \mathrm{~h}$ of life.

\section{Insulin in Urine}

The erythroblastotic infants were divided into two groups (tables I and II). Group 1 comprised 12 infants older than 36 weeks gestation, and group 2 comprised 10 infants younger than 36 weeks gestation. The infants in group 1 had a mean insulin/creatinine ratio of $18.0 \mu \mathrm{U} / \mathrm{mg}$ compared with the normal term control group mean of $5.4 \mu \mathrm{U} / \mathrm{mg}$. This difference was significant at $P<0.01$. Cord hemoglobin levels for group 1 infants ranged from 4.3 to $17 \mathrm{~g} / 100 \mathrm{ml}$. Six of the 12 infants (group I A) had cord hemoglobins greater than $13 \mathrm{~g} / 100 \mathrm{ml}$. Their urinary insulin/creatinine ratio was $6.9 \mu \mathrm{U} / \mathrm{mg}$ (mean+sEM 10; mean-SEM 4.7). This was not significantly different from the mean of $5.4 \mu \mathrm{U} / \mathrm{mg}$ (mean+SEM 6.1; mean-SEM 4.9) of the normal term infants $(P=0.5)$. None of these infants became hypoglycemic. The remaining six infants (group IB) all had hemoglobin levels less than $13 \mathrm{~g} / 100 \mathrm{ml}$ and required at least one exchange transfusion within the first $24 \mathrm{~h}$ of life. The level of insulin in their urine was $47.0 \mu \mathrm{U} / \mathrm{mg}$ (mean+SEM 64.4 ; mean-SEM 34.4). This was significantly different from the normal term control group $(P<0.01)$. One of these six infants became hypoglycemic. 
Group 2 consisted of 10 infants born prematurely. Seven had received at least one intrauterine intraperitoneal transfusion (IUPT), and all had at least one exchange transfusion within the first $24 \mathrm{~h}$ of life. The mean level of excretion of insulin was $129.7 \mu \mathrm{U} / \mathrm{mg}$ (mean + SEM 186.9; mean-SEM 90.1) which was significantly different from the mean level of $21.9 \mu \mathrm{U} / \mathrm{mg}$ (mean + sem 27.2; mean-sem 17.9) $(P<0.01)$ characteristic of the premature infants of the control group.

Insulin in Urine and Blood Glucose

The mean blood glucose level during the period of the urine collection correlated inversely with excretion of insulin in urine $(r=-0.676, P<0.01)$. Infants who were more severely affected had the highest excretory levels of insulin in the urine and the lowest concentrations of glucose in blood (fig.2).

\section{Cord Hemoglobin and Insulin in Urine}

A measure of the severity of the hemolytic disease is found in the hemoglobin from the cord. There was an inverse correlation between cord hemoglobin and insulin excreted $(r=-0.64 ; P<0.01)$. The cord hemoglobin, however, is likely to be higher than anticipated in those infants who had received intrauterine intraperitoneal transfusions. When these infants are excluded the correlation coefficient increases to $r=$ -0.84 (fig. 3 ).

Table I. Estimation of insulin in urine and clinical data in 22 erythroblastotic babies

\begin{tabular}{|c|c|c|c|c|c|}
\hline Babies & $\begin{array}{l}\text { Gestation, } \\
\text { wk }\end{array}$ & $\begin{array}{l}\text { Cord hemoglobin, } \\
\qquad \mathrm{g} / 100 \mathrm{ml}\end{array}$ & $\begin{array}{l}\text { No. of intra- } \\
\text { peritoneal } \\
\text { transfusions }\end{array}$ & $\begin{array}{l}\text { No. of exchange } \\
\text { transfusions in } \\
\text { first } 24 \mathrm{~h}\end{array}$ & $\begin{array}{l}\text { Insulin/creatinine } \\
\text { ratio during 1st } 24 \mathrm{~h} \text {, } \\
\mu \mathrm{U} / \mathrm{mg}\end{array}$ \\
\hline \multicolumn{6}{|c|}{ Group $1 \mathrm{~A}$} \\
\hline 1 & 39 & 15.0 & 0 & 0 & 1.8 \\
\hline 2 & 37 & 13.8 & 0 & 0 & 9.8 \\
\hline 3 & 39 & 14.5 & 0 & 0 & 12.0 \\
\hline 4 & 38 & 15.9 & 0 & 0 & 10.0 \\
\hline 5 & 38 & 13.8 & 0 & 0 & 18.0 \\
\hline 6 & 37 & 17.0 & 0 & $1^{1,4}$ & 2.9 \\
\hline \multicolumn{6}{|c|}{ Group 1B } \\
\hline 7 & 38 & 10.4 & 0 & $1^{1,4}$ & 20.0 \\
\hline $8^{2}$ & 38 & 4.3 & 0 & $1^{3,4,5}$ & 96.0 \\
\hline 9 & 38 & 7.7 & 0 & 11,4 & 89.0 \\
\hline 10 & 38 & 8.8 & 0 & $1^{1,4}$ & 41.0 \\
\hline 11 & 36 & - & 0 & 11,4 & 86.0 \\
\hline 12 & 37 & 12.6 & 0 & 11,4 & 18.0 \\
\hline \multicolumn{6}{|c|}{ Group 2} \\
\hline 13 & 35 & 9.3 & 0 & $2^{1,4}$ & 221.0 \\
\hline $14^{2}$ & 30 & 7.6 & 0 & $1^{3,5}$ & 153.0 \\
\hline 15 & 35 & 9.9 & 0 & $1^{1,4}$ & 14.0 \\
\hline 16 & 32 & 7.7 & 1 & $1^{3,5} 1^{1}$ & 150.0 \\
\hline 17 & 31 & 12.9 & 1 & $1^{1,4}$ & 49.0 \\
\hline 18 & 34 & 14.2 & 3 & $1^{1,4}$ & 53.0 \\
\hline $19^{2}$ & 34 & 3.4 & 1 & $1^{1,4}$ & 97.0 \\
\hline $20^{2}$ & 30 & 7.1 & 1 & $1^{1,4}$ & 762.0 \\
\hline 21 & 34 & 14.1 & 3 & $1^{1,4}$ & 410.0 \\
\hline $22^{2}$ & 33 & 8.6 & 1 & $1^{3,5} 1^{1}$ & 243.0 \\
\hline
\end{tabular}

1 Fresh heparinized blood used for exchange transfusions.

2 Infants who died in the neonatal period.

${ }^{3}$ Acid citrate dextrose blood used for exchange transfusions.

${ }^{4}$ Exchange transfusion carried out during urine collection.

${ }^{5}$ Infant was hypoglycemic prior to exchange transfusion. 
Table II. Summary of data on insulin in urine

\begin{tabular}{lrrrr}
\hline Babies & $\begin{array}{c}\text { Gesta- } \\
\text { tion, } \\
\text { wk }\end{array}$ & \multicolumn{2}{c}{$\begin{array}{c}\text { Insulin/creatinine } \\
\text { ratio, } \mu \mathrm{U} / \mathrm{mg}\end{array}$} \\
\cline { 3 - 6 } & & Mean & + sEM & - SEM \\
\hline Group 1 A $(6)^{1}$ & $36-39$ & 6.9 & 10.0 & 4.7 \\
Group 1 B $(6)$ & $36-39$ & 47.0 & 64.4 & 34.4 \\
Healthy term infants (45) & $36-42$ & 5.4 & 6.1 & 4.9 \\
Group 2 (10) & $30-36$ & 129.7 & 186.9 & 90.1 \\
Healthy premature & & & & \\
infants (13) & $29-36$ & 21.9 & 27.2 & 17.9 \\
& & & &
\end{tabular}

${ }^{1}$ Number in parentheses indicates number of patients.

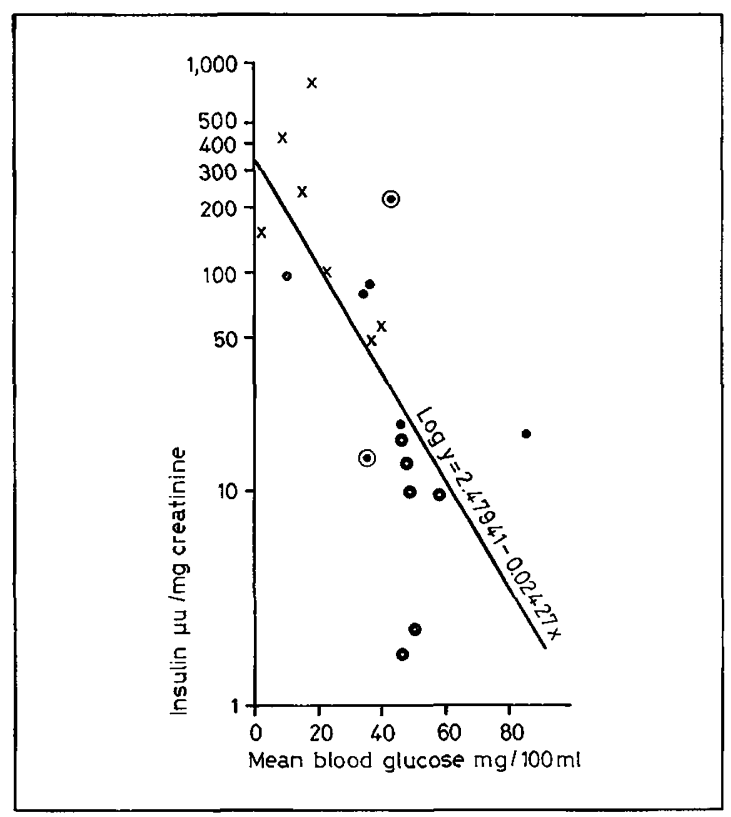

Fig. 2. Correlation of excretion of insulin in urine with mean levels of glucose in blood in 20 erythroblastotic infants $(r=-0.676 ; P<0.01)$. 0 : group 1 A. $\bullet$ : group 1B. $\odot$ : group 2, no intrauterine intraperitoneal transfusion. $\times$ : group 2 , intrauterine intraperitoneal transfusion.

Fig.4. Correlation of lowest level of glucose in blood with cord hemoglobin in 28 erythroblastotic infants. The regression line calculated excludes the infants who received intrauterine intraperitoneal transfusions $(r=$ $0.787 ; P<0.01)$. $O$ : group $1 \mathrm{~A}$, infants with cord hemoglobin $>13 \mathrm{~g} / 100 \mathrm{ml}$. $\bullet$ : group $1 \mathrm{~B}$, infants with cord hemoglobin $<13 \mathrm{~g} / 100 \mathrm{ml}$. $\times$ : group 2 , infants with intrauterine intraperitoneal transfusion. $\odot$ : group 2 , no intrauterine intraperitoneal transfusion.

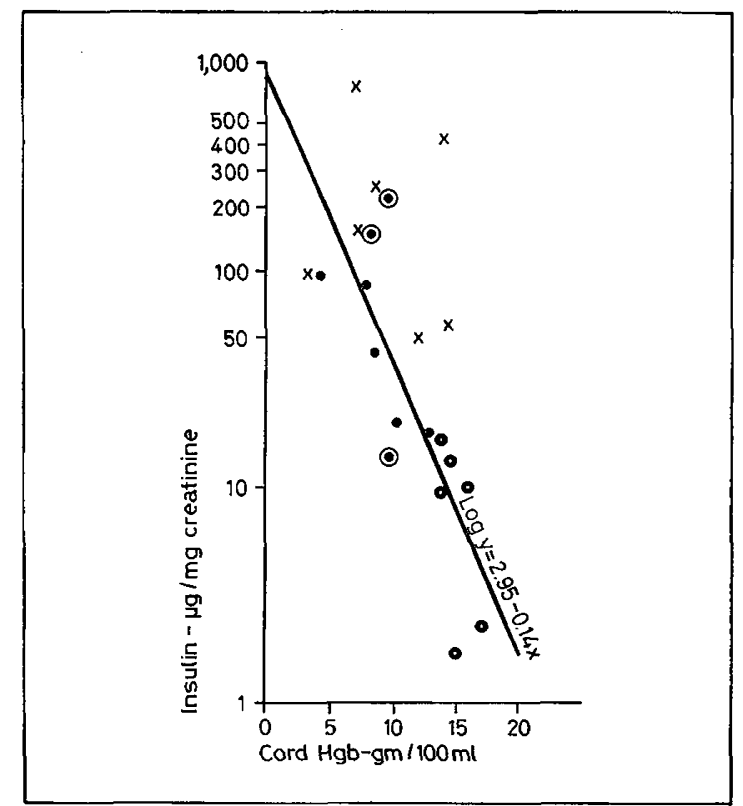

Fig.3. Correlation of excretion of insulin in urine and cord hemoglobin in 21 erythroblastotic infants. The regression line calculated excludes infants who received intrauterine intraperitoneal transfusion $(r=-0.84$; $P<0.01)$. O: group $1 \mathrm{~A}$, infants with cord hemoglobin $>13 \mathrm{~g} / 100 \mathrm{ml}$. : group $1 \mathrm{~B}$, infants with cord hemoglobin $<13 \mathrm{~g} / 100 \mathrm{ml}$. $\odot$ : group 2 , no intrauterine intraperitoneal transfusion. $\times$ : group 2 , intrauterine intraperitoneal transfusion.

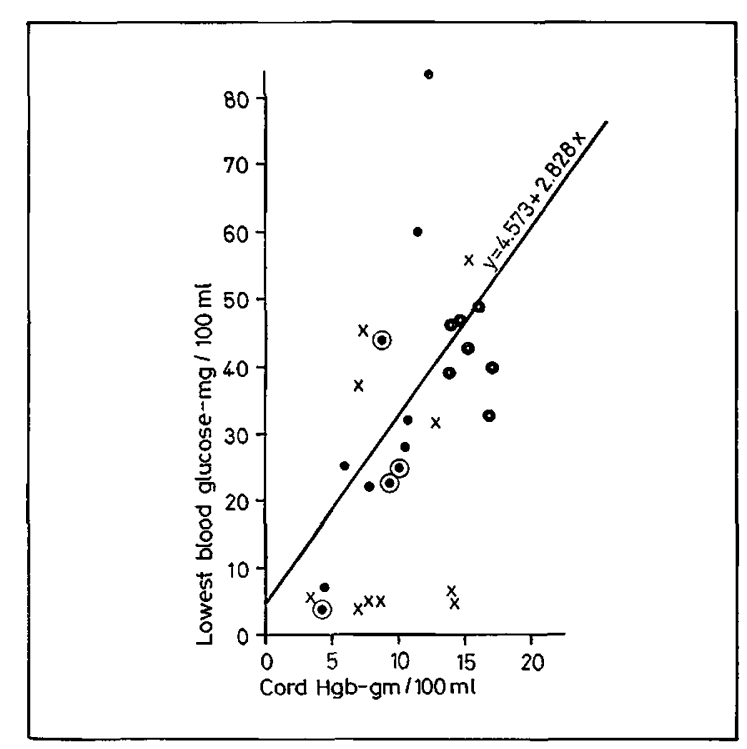




\section{Cord Hemoglobin and Glucose}

A positive correlation was obtained between the lowest glucose level and the cord hemoglobin $(r=$ $0.51 ; P<0.01)$ for 27 erythroblastotic infants studied. Eliminating those infants who had received intrauterine intraperitoneal transfusions, the correlation coefficient rises to $r=0.787$. Of the seven infants who had become hypoglycemic, six had hemoglobin levels of less than $9 \mathrm{~g} / 100 \mathrm{ml}$; only one had a hemoglobin of $14.1 \mathrm{~g} / 100 \mathrm{ml}$. This infant, however, had received three intrauterine intraperitoneal transfusions between 26 and 33 weeks gestation (fig. 4).

\section{Discussion}

The occurrence of both hypoglycemia and hyperplasia of the pancreatic islet cells in erythroblastotic infants suggests the secretion of excessive amounts of insulin. This conclusion cannot be substantiated from the morphological appearance of the cells alone: measurement of the secretory activity of the islet cells is necessary. Indirect estimates of secretory activity can be obtained either by measurement of insulin in serum or in urine. Insulin excretion in urine has been shown to reflect serum levels in both adults $[10,11]$ and newborns [6]. This study demonstrates that the erythroblastotic infant was excreting greater amounts of insulin in urine when compared with a normal control group of similar gestational age, and that the more severely affected the infant, the greater the amount of insulin excreted. The inverse correlation between glucose level and excretion of insulin in urine suggests that the hypoglycemia is caused by a hyperinsulinemic state (as it is in infants of diabetic mothers). This is in agreement with the findings of RArvio and OSTERLUND [9]. Insulin in the urine in the control premature group was significantly elevated when compared with data from the control term group $(P<0.01)$. The cause of this difference is not clear, but may be related to the handling of insulin by the kidney. The observations of Chamberlatn and Strmmler [2], that potentially large changes in excretion of insulin in urine in adults may be induced by changes in renal tubular handling of insulin, is in accord with this view. This factor may contribute in part to the elevated levels of insulin in urine in the premature infants studied, but it does not account for the more than sixfold difference observed between erythroblastotic infants and their respective controls.

The mechanism of hyperinsulinism remains obscure. Steinke et al. [13] have suggested that glutathione released by the hemolyzed cells destroys insulin, causing a compensatory increase in insulin production. Since the hemolytic process continues after birth, how- ever, the increased rate of insulin destruction should continue; thus, this theory would not explain the hypoglycemia seen in the immediate postnatal period.

Increased insulin destruction by the placenta, which is rich in insulinase and commonly hyperplastic in severe cases of hemolytic disease, might account for these findings. Sèparation of the infant from the placenta would lead to an abrupt decrease in the infant's rate of insulin destruction and could lead to a temporary overproduction of insulin, leading to hypoglycemia. Such a hypothesis would explain the observation that the erythroblastotic infants studied were not large for their gestational age; a sign that hyperinsulinism is of relatively recent onset, and thus, does not influence the growth of the fetus. This is in contrast to the infants of diabetic mothers who excrete excessive quantities of insulin both in utero and in the immediate postnatal period.

The correlation between cord hemoglobin and blood glucose indicates that blood glucose should be monitored early in all erythroblastotic babies, particularly those with low cord hemoglobin levels. Blood glucose should also be determined in all infants who have received intrauterine intraperitoneal transfusions, since the hemoglobin level might be higher than anticipated. Indeed, one such infant in this study with a hemoglobin of $14.1 \mathrm{~g} / 100 \mathrm{ml}$ became hypoglycemic.

\section{Summary}

Blood glucose levels and excretion of insulin in urine were measured in 31 erythroblastotic infants. Twentytwo infants had insulin estimations in urine performed during the first $24 \mathrm{~h}$ of life. Cord hemoglobin was used as the index of severity of the disease. The erythroblastotic infant was found to be excreting greater amounts of insulin when compared with a normal control group of like gestational age; the more severely affected the infant, the greater the amount of insulin excreted. Excretion of insulin was inversely related to blood glucose. Hypoglycemia occurred in seven of the most severely affected infants, all of whom showed elevated levels of insulin in urine. Estimation of insulin in urine provides a simple and safe index of beta cell secretory activity.

\section{References and Notes}

1. BArrett, C.T. and Oliver, T.K., Jr.: Hypoglycemia and hyperinsulinism in infants with erythroblastosis fetalis. New Engl.J.Med. 278: 1260 (1968).

2. Chamberlain, M.J. and Stimmler, L.: The renal 
handling of insulin. J.clin. Invest. 46: 911 (1967).

3. Driscol, S. G. and Steinke, J.: Pancreatic insulin content in severe erythroblastosis fetalis. Pediatrics 39: 448 (1967).

4. Hazeltine, F.G.: Hypoglycemia and Rh erythroblastosis fetalis. Pediatrics 39: 696 (1967).

5. Liebegotr, G.: Über das familiäre Vorkommen angeborener Zystennieren. Beitr.path. Anat. 101: 606 (1938).

6. Lowy, C. and Schiff, D.: Urinary excretion of insulin in the healthy newborn. Lancet $i: 225$ (1968).

7. Mrller, H.C.; Johnson, R.D. and Durlacher, S.H.: A comparison of newborn infants with erythroblastosis fetalis with those born to diabetic mothers. J. Pediat. 24: 603 (1944).

8. Potter, E.L.; Sickel, H.P.G. and Stryker, W. A.: Hyperplasia of islets in rhesus babies. Arch. Path. 31: 467 (1941).

9. Raivio, K. and Osterlund, K.: Hypoglycemia and hyperinsulinemia associated with erythroblastosis fetalis. Pediatrics 43: 217 (1969).

10. Rubenstein, A.H.; Lowy, G. and Fraser, T.R.: Radioimmunoassay of insulin in urine. Diabetologia 3: 453 (1967).

11. Rubenstein, A.H.; Lowy, G.; Welborn, T.A. and Fraser, T.R.: Urine insulin in normal subjects. Metabolism 16: 234 (1967).

12. Smallperce, V. and Davies, P.A.: Immediate feeding of premature infants with undiluted breast milk. Lancet $i i$ : 1349 (1964).
13. Steinke, J.; Gries, F.A. and Driscoll, S. G.: In vitro studies of insulin inactivation with reference to erythroblastosis fetalis. Blood 30: 359 (1967).

14. Stevens, J.F.: Biochemical changes in the blood of the newborn. J.med.Lab.Tech. 22: 47 (1965).

15. The authors are grateful to the Wellcome Trust, the Nuffield Foundation and the Sir William Coxan Trust Fund for facilities; Prof. J.A. Davis, T. RusselL Fraser and J.P. M.Tizard for their advice and encouragement; Miss Linda CalcuTt, Mrs. D. HaRRIs, and Mr. R. SAWH for their technical assistance; and the Nursing Staff of the Neonatal Ward, Hammersmith Hospital, for their cooperation.

16. Dr. C. Lowy is Registrar at the Department of Medicine, Hammersmith Hospital, and is presently a research associate, Harvard Medical School. Dr. D. SchrfF is a clinical demonstrator in the Department of Pediatrics, McGill University and Assistant, Neonatal Intensive Care Unit, Montreal Children's Hospital.

17. Insulin standard obtained from the Medical Research Council of Great Britain and from the Novo Laboratories, Copenhagen, Denmark.

18. Consent to study the normal infants and sick infants was obtained from the parents at the time of the institution of the study.

19. Requests for reprints should be addressed to: Dr. D. SchIFF, McGill University, Montreal Children's Hospital Research Institute, 2300 Tupper Street, Montreal 108, Quebec, Canada.

20. Accepted for publication October 22, 1969. 